DOI: http://dx.doi.org/10.22201/iie.18703062e.1969.38.876

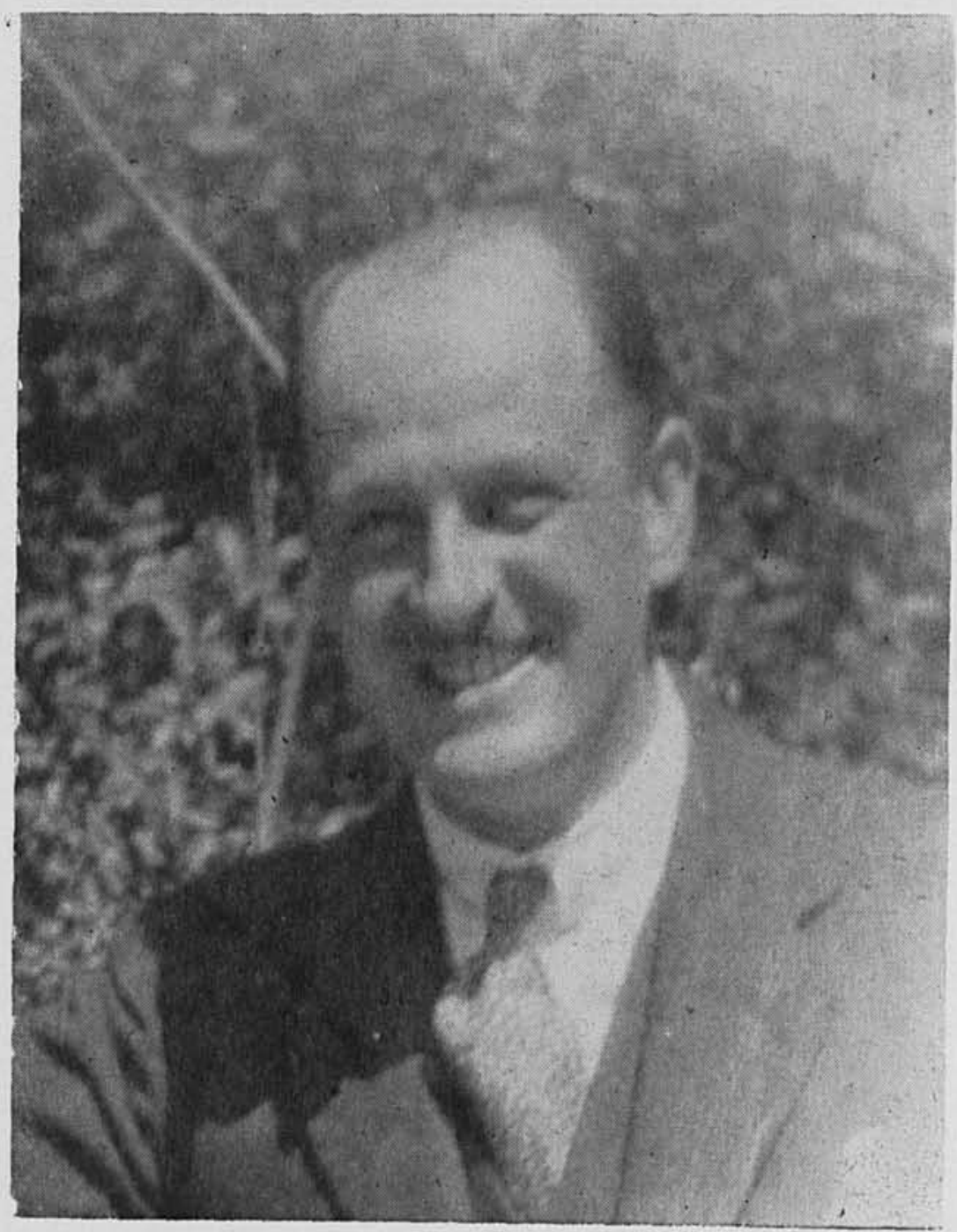

1. Manuel Romero de Terreros, en 1922 
DOI: http://dx.doi.org/10.22201/iie.18703062e.1969.38.876

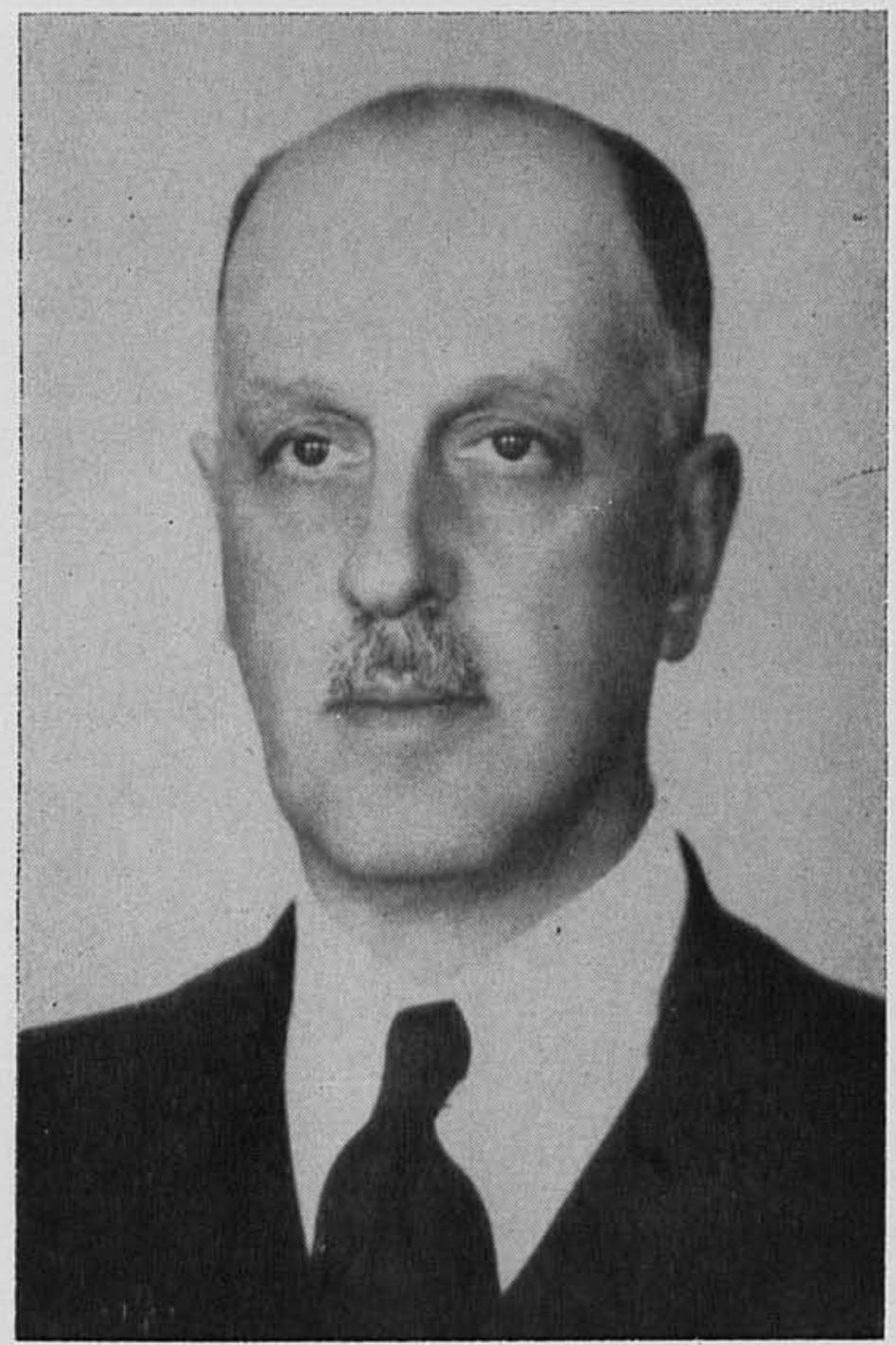

2. Manuel Romero de Terreros, en 1940 
DOI: http://dx.doi.org/10.22201/iie.18703062e.1969.38.876

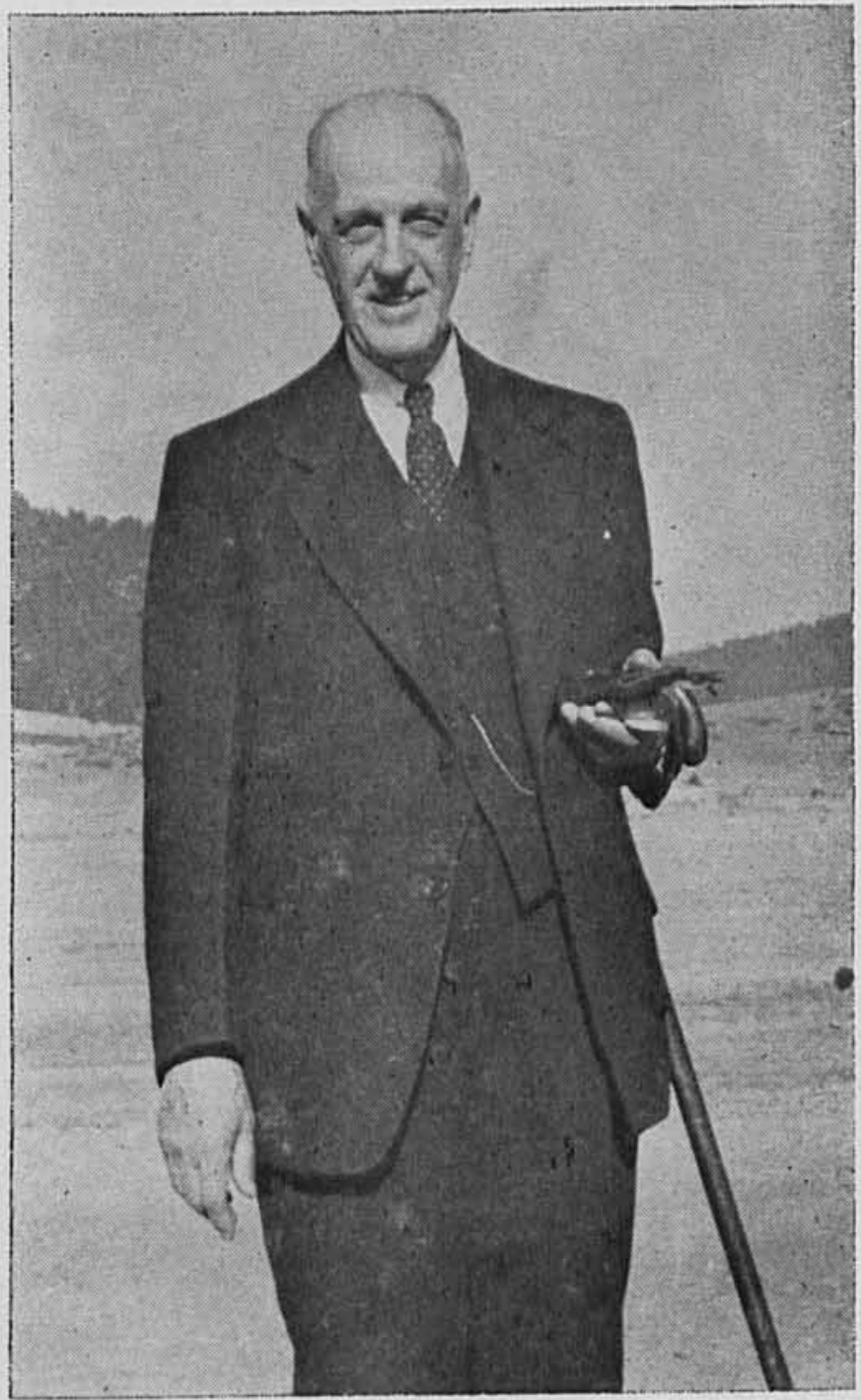

3. Manuel Romero de Terreros, en 1948 
DOI: http://dx.doi.org/10.22201/iie.18703062e.1969.38.876

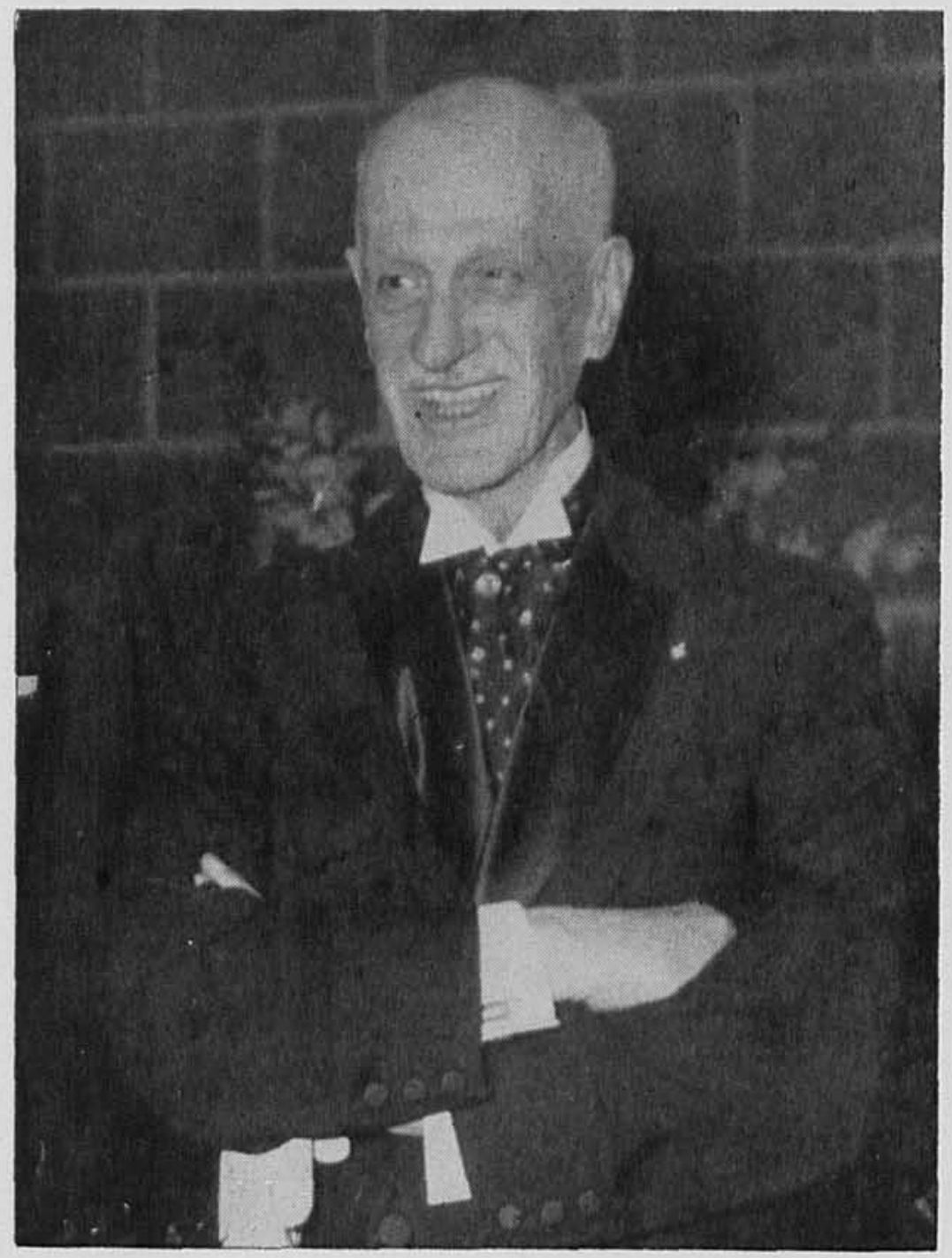

4. Manuel Romero de Terreros, en 1957 


\section{MANUEL ROMERO DE TERREROS Y VINENT (1880-1968) Y SU OBRA *}

Por Justino Fernández

Recordar aquí y ahora a don Manuel Romero de Terreros y Vinent equivale a considerar no sólo a uno de los académicos más distinguidos que hayan formado parte de esta noble institución, sino sobre todo a un ilustre intelectual mexicano que con su vasta obra contribuyó de manera notable a la cultura de nuestro país en el presente siglo. En efecto, su continua labor en varios aspectos de la historia y en la del arte en particular, forma un conjunto de cerca de quinientos trabajos que enriquecen la cultura nacional, y por ende la universal, y cuyo conocimiento es imprescindible para quien se interese en los estudios históricos sobre la Nueva España y el México de la pasada centuria.

Escritor de fina sensibilidad y de excepcional buen gusto, en sus trabajos priva una elegancia en que están ausentes, de manera natural, los rebuscamientos de ideas y de estilo; así, su prosa es siempre clara, diáfana, de gestación clásica. Claro está que su estilo es expresión de su personalidad, de su carácter. Para el crítico nada hay más revelador que la obra misma; pero también ilumina la comprensión de ella el conocimiento de los antecedentes biográficos del escritor o de cualquier artista. Por eso es necesario tenerlos presentes al rendir homenaje a la memoria de don Manuel Romero de Terreros y Vinent.

Bien sabemos que fue de noble cuna, de larga tradición en nuestro pais; nació en México el 24 de marzo de 1880 y fue hijo de don Alberto Romero de Terreros y Gómez de Parada y de doña Ana Vinent y Kindelan, de la casa de los marqueses de Palomares del Duero. El título de Marqués de San Francisco que ostentó don Manuel, y que aparece junto con su nombre en algunos de sus trabajos, lo heredó de su tío, el marqués de la Pedreguera. Entre sus ilustres antepasados figura don Pedro Romero de Terreros, quien fue el fundador, en el siglo xviri, de esa benemérita institución que es el Nacional Monte de Piedad. Fue Caballero de Honor y Devoción de la Inclita y Soberana Orden de Malta.

Alguien podría pensar que con tal abolengo fuese don Manuel un altivo sefior, pero justamente era lo contrario: la imagen de la sencillez

- Discurso lefdo en la Academia Mexicana, Correspondiente de la Espanfola, el 6 de diciembre de 1968 en la sesión dedicada a la memoria de don Manuel Romero de Terretos y Vinent. 
y de la bondad; era un hombre que tuvo un agudo sentido de la proporción y un temple interior que le hizo sobrevivir a las calamidades de la vida. No es dato despreciable que haya pasado su primera juventud en Inglaterra; estudió en el famoso Colegio de Stonyhurst y presentó exámenes en las universidades de Oxford y de Cambridge; se formó pues en un ambiente que, por lo general, imprime carácter a un espiritu sensible; y dominó la lengua de Shakespeare tan pulidamente como la de Cervantes.

Regresó a México en 1900, cuando tenía veinte años de edad; aquí casó, a los 41, con doña Concepción de Garay y Kattain, amante esposa llena de virtudes y compañera en todos los intereses del espiritu y del intelecto que ocuparon su vida. Rodeado de sus hijos, hijas y nietos, don Manuel era un patriarca que derramaba su cariño a todos, y aún le alcanzaba para extenderlo a parientes y amigos. Nada le hizo cambiar su bondadosa actitud que, junto con cierto estoicismo, tomaba fuerza de su fe religiosa. Era la imagen viva del caballero, auténtico en todo, $y$ en todo ejemplar.

Fue profesor de literatura inglesa y de otras disciplinas en la Escuela de Altos Estudios, y continuó como tal en la Facultad de Filosofía y Letras y en la Escuela de Verano de la Universidad Nacional Autónoma de México; por veintidós años fue miembro del Instituto de Investigaciones Estéticas, de la misma Universidad, y en él desarrolló una labor continua, de la que son muestra los numerosos estudios con que contribuyó al conocimiento del arte mexicano. También fue presidente y patrono del Nacional Monte de Piedad, fundado, como se ha dicho, por uno de sus antepasados.

Sus méritos de escritor y de historiador fueron ampliamente reconocidos en nuestro pais y en el extranjero; fue académico de número de esta Academia Mexicana Correspondiente de la Española, en la que ocupó en 1918 la silla que habla dejado vacante el erudito don Francisco del Paso y Troncoso; y fue académico de la Academia Mexicana de la Historia, y su presidente por largos años. También fue correspondiente de la Academia de Bellas Artes de San Fernando, de Madrid; de la de los Arcades de Roma, en ésta con el nombre de Gliconte Tirio; del Colegio Heráldico de Roma, y del Consejo Heráldico de Francia, y también perteneció como miembro a otras instituciones de cultura nacionales y extranjeras.

Ajeno a toda ostentación, costó cierta insistencia que permitiera al Instituto de Investigaciones Estéticas publicar su extensa bibliografía 
en 1961, la que, adicionada por don José Miguel Quintana, volvió a editarse cuatro años después en el Boletín Bibliográfico de la Secretaria de Hacienda y Crédito Público.

Cuanto hemos dicho hasta aquí, y más que podría agregarse, es tan sólo el marco de referencias biográficas dentro del cual se encuentra su obra de escritor, de historiador y de crítico de arte.

Nos duele la desaparición del entrañable amigo, más por el respeto y admiración que le guardamos, y para completar el perfil de don Manuel, nos interesa especialmente revisar su obra, así sea superficial y brevemente, porque es ella por sf misma la que le da un lugar distinguido en nuestra cultura. No es tarea fácil enterarse de cuándo escribió, ni abarcar su obra por entero con profundidad; ése es trabajo que hemos de dejar para otra ocasión; por ahora, extendamos la mirada siquiera a las variadas disciplinas y temas que trató a lo largo de su vida, todo lo cual merece otro tipo de estudios. Así pues, basándonos en su bibliografía, es posible caer en cuenta, gracias a una breve labor estadística, de cuáles fueron los temas en que se ocupó mayormente, o a cuáles disciplinas contribuyó con sus trabajos.

Su primer artículo, en 1905, fue de carácter bibliográfico; siguió más tarde, la Bibliografía de los cronistas de la ciudad de México (1926) y el "Ensayo bibliográfico de la pintura en México durante la época colonial"; pero interesa en especial su opúsculo sobre La bibliografia de Luis Lagarto (1950), tanto por tratar del excelente miniaturista del siglo xvir, vecino de Puebla, como por el sentido que don Manuel le dio. En efecto, el inventario de los libros va precedido de un estudio sobre el arte, la familia y la librería del pintor, con objeto de poner en relación los intereses del artista con sus libros, ya que, dice: "Demuestran... que Luis Lagarto era hombre de amplia cultura y marcado buen gusto literario."

A la Heráldica le dedicó don Manuel no menos de nueve trabajos especificos, si bien en otros estudios históricos sus conocimientos en esa disciplina, tan raramente cultivada, se manifiestan en relación con diversos personajes. Salvo algunos estudios de carácter especial, su interés está centrado en la Nueva España, en las armas de los conquistadores $y$ en los títulos nobiliarios de las familias mexicanas.

Otro aspecto de los intereses del historiador es la Genealogia, en donde fue uno de los pocos estudiosos que le han prestado atención. Sus trabajos se refieren a personajes o familias mexicanas de la época colonial, algunas emparentadas con don Manuel; destaca su estudio sobre Herndn 
Cortes, sus hijos y nietos, caballeros de las Ordenes Militares, que merecio una reedición (14 1919, 241944). Mas, con el buen sentido de historiadok que tuvo don Manuel, siempre puso en relación los datos con la vida y, asf, sus estudios genealógicos tienen por interés las biografias, de las cuales escribió varias de personajes de la Nueva España, algunos, repito, pertenecientes a su propia familia.

Se ocupó también en las "Órdenes Militares en México"; en la de Malta, de la cual fue Caballero como ya anotamos, y tiene especial interés su trabajo sobre "La guardia de alabarderos de los virreyes de la Nueva España."

Asimismo, pocos son los estudiosos que se han dedicado en México a la Numismática, disciplina en que don Manuel fue experto y sobre la cual publicó buen número de trabajos que abarcan nuestra historia moderna, desde la Nueva España, "Los tlacos coloniales", hasta el México Independiente, "El peso de Victoria", "El peso de Maximiliano" y de manera especial se ocupó en "Las monedas de la Revolución"; escribió interesantes estudios sobre la "Moneda henequenera"; las "de necesidad, de Michoacán", y la de Colima, y todo lo resumió en un artículo titulado "Cuatro siglos de Moneda Mexicana" (1936).

Acerca de otras historias y artes no mexicanos escribió don Manuel algunos ensayos. De la Historia europea sobre "Los Arcades de Roma", "Los duques de Norfolk", "El barón de Ripperdá" y "La pompa imperial." Dos artículos encontramos sobre Pintura europea, "El retrato de doña Ana de Austria", por Carreño de Miranda, que pertenece a nuestras colecciones del Museo de San Carlos, y "Retratos reales que se han perdido", entre ellos el de Carlos V, de Tiziano, que pereció en el incendio del Palacio Virreinal de México durante el siglo Xvir. También escribió sendos artículos sobre "Bronces del antiguo Japón" y sobre "Miniaturas persas", ambos relativos a la Historia de las artes orientales.

Nociones de literatura castellana tituló un opúsculo que apareció en 1926 y que, ampliado, se publicó en Boston el año siguiente. En inglés compuso Una breve antologia de prosa mexicana, con notas biográficas de los autores, que fue editada en Stanford, California (1928), para difundir, en páginas selectas, el conocimiento de nuestros valores literarios.

La literatura fue uno de sus intereses, y amén de algunos escarceos previos, en 1922 publicó la primera edición de La puerta de bronce y otros cuentos, que por segunda vez fue editada en 1957. Es una interesante colección de relatos que hoy día entran con honor en el género 
que se llama literatura fantástica; su lectura es muy atractiva, pues, coin la sencillez característica de su pluma, cada uno de los cuentos está construido de manera que lleve al lector en suspenso al desenlace final; son de carácter romántico y en ellos surgen los ambientes del México de nuestros abuelos, mas todos tienen un acento macabro, imusitado en un escritor como don Manuel, quien dejaba libre su imaginación recreando el misterio del "más allá".

También escribió pequeñas obras teatrales y algunas de ellas fuerón reunidas en un volumen que titulo Teatro breve (1956). Salvo una de ambiente antiguo que es trágica, "La confeșión" se llama, las cinco restantes se desarrollan en nuestro tiempo y, no obstante, tienen -menos una, "Intuición", en que luce su ironía y humorismo-, un sentido fantástico, macabro, o tragicómico; inclusive en alguna, "Luciferina", entra en juego el sueño y por medio de él se cuela "el otro mundo" dejando al lector abierta la cuestión de si "la vida es sueño", todo en plan de comedia que hace recordar algunas obras breves de Pirandello. Como sus cuentos, sus piezas teatrales están compuestas de manera que tengan un dramático final, o bien en alguna, "Casa de huéspedes", que el drama se resuelva en buen humor. Ciertamente don Manuel tenía aptitudes de dramaturgo y con ellas iban su sentido de gracia y de imaginación.

Entre las varias traducciones del francés y del inglés que realizó, se encuentran las de obras de autores como Keats y Lord Dunsany; del primero, "La bella dama sin piedad", y del segundo, "Los enemigos de la reina"; de Andersen tradujo "El ruiseñor", y de Middleton "Los hijos de la Luna."

No se ocupó mucho en hacer recensiones, pero a lo menos escribió unas diez y seis, casi todas referentes a estudios sobre arquitectura, obras de arte y de artes menores, que fueran uno de sus intereses importantes.

Don Manuel Romero de Terreros leyó su discurso de ingreso en esta Academia Mexicana, Correspondiente de la Real Española, el 22 de abril de 1919, en su recepción como Individuo de Número de la misma, y el tema que trató fue original: "El estilo epistolar en la Nueva España", del cual presentó variadas muestras y acertadas consideraciones. En su excelente discurso dice algo que explica el por qué de sus afanes. de historiador: "La afición decidida que (tengo) a la historia de Méjico -escribió- especialmente en lo que se refiere a los tres siglos coloniales. Es indudable que la sangre hispana, que heredé de mis mayores, háceme ver con simpatía todo cuanto a la Madre Patria se refiere, y por eso, he 
dedicado mis modestos estudios a aquella época en que la Nueva España se llamaba con orgullo hija predilecta de la Vieja."

Lo anterior parece el prólogo más adecuado a la parte de su obra que en seguida hemos de considerar, pero antes queremos recoger otras palabras del mismo discurso que explican también la conciencia de su propio estilo de escritor, pues al referirse a una carta del conde de Regla lo alaba diciendo: "En ella, ni la hipérbole ni el gongorismo tienen cabida: al contrario, la sobriedad y la sencillez son sus mejores galas"; no obstante tal gusto en cuanto al lenguaje, don Manuel fue capaz de estimar y aun de entusiasmarse por nuestro arte barroco y es que, en verdad, supo distinguir entre el objeto de su admiración y la forma de escribir sobre él.

Considerados sus trabajos sobre el pasado colonial se advierten tres grupos de ellos: el primero sobre temas variados de historia politica, que incluye cerca de ochenta estudios breves; el segundo se refiere a otros tantos "bocetos", como él los llamó, de la vida social de la Nueva España; y el tercero, igualmente numeroso, sobre otro aspecto en el que fue autoridad: el arte en México durante el Virreinato.

Parece conveniente explicar el modo, que constituye un método, con que don Manuel escribió sus estudios históricos. Salvo excepciones, casi todos fueron concebidos para ser publicados en diarios y revistas, de éstas algunas de carácter informativo y de divulgación y otras especializadas, técnicas y cientificas. Más tarde recogió en volúmenes distintos buena parte de sus artículos. Ahorá bien, esa manera de expresión, lejos de ser censurable, cuenta con representantes ilustres, de los cuales mencionaremos sólo dos, a José Ortega y Gasset, en España, y a Antonio Caso, en México, si bien podrla formarse una larga lista. Esa manera convenia al modo de ser de don Manuel y lo obligaba a la brevedad de sus escritos, lo que él mismo, por su modestia, consideraba una cualidad. Mas esto no quiere decir que sus estudios carecieran de información $y$, en muchos casos, de investigación; por el contrario, siempre se puede depender de los muchos datos, inéditos en su mayor parte, y de los documentos que dio a conocer. Pero como tuvo un auténtico sentido literario, sabia sintetizarlo todo y expresarlo en forma clara y atractiva, to que añade un alto valor a sus estudios, que tienen la cualidad de interesar a toda clase de lectores: al estudioso de la historia por su novedad y buen sentido, y al público en general por lo ameno de la narración. Ciertamente recuerdan a otro historiador mexicano, don Luis González Obregón, quien tuvo intereses semejantes a los de don Manuel, y quien 
prologó uno de sus libros. Entre ambos nos descubrieron muchos aspectos desconocidos $\mathbf{u}$ olvidados de nuestro pasado.

Don Manuel publicó varias series de artículos bajo títulos generales: "Cosas que fueron", es uno de ellos, "Viejos libros. Viejos papeles", es otro, y para sus bocetos de la vida social, uno más, en latín: "Ex Antiquis."

En cuanto a los estudios que pueden agruparse en la historia política, considerada esta en un amplio sentido, se refieren a muy diversos temas. A Hernán Cortés y a sus descendientes les dedicó varios trabajos, otros a don Vasco de Quiroga, a algunos de los conquistadores, a los bergantines y a la encomienda de Martín López, a los corregidores, a los cronistas de la ciudad de México, a los virreyes y a otros personajes, como los condes de Regla y a los Terreros, siendo Pedro, uno de ellos, el primer español que pisó el Continente Americano. Otros temas son curiosos e inusitados, como el de la estación de bomberos en el siglo xvir, la primera historia del desagüe de México, un bibliófilo en el Santo Oficio, un quilatador mexicano, un intento pecuario, el primer mexicano en Inglaterra, un inca en México, un catecismo testeriano, coleccionistas de otros tiempos, y aun se ocupa de las guias de forasteros, de los billetes del Monte de Piedad, de las tarjetas de visita, del estilo epistolar y de otros muchos asuntos. Son de particular interés ciertas "estampas", como la de la Villa de Guadalupe en la segunda mitad del siglo XviI, la celebración de los plateros de la Jura de Carlos IV, la calle del Reloj y la Plaza Mayor en 1729. Un trabajo se refiere al origen de la ciudad y puerto de Tampico y otro más sobre un proyecto de independencia de México. Ya se ve por las muestras anteriores que no hubo aspecto, por desdeñable que pudiera parecer, que no incitara la curiosidad y el interés del historiador.

Por el justo concepto de la historia que tuvo don Manuel, para él historiar era tanto como recrear la vida del pasado, no entregar datos en abstracto. Ast, parece natural que le interesara particularmente la vida social en la Nueva España; es, en verdad, uno de los pocos estudiosos que nos han dado multitud de aspectos desconocidos que él mismo llamó modestamente "menudencias de nuestra historia", pero que integran una visión verdadera, y por demás atractiva, de la vida de entonces. Si bien sus trabajos fueron publicados como articulos, la mayor parte de ellos quedaron reunidos en cuatro volúmenes: Bocetos de la vida social en la Nueva España (1+ ed. 1919, $2^{4}$ ed. 1944), Siluetas de antaño (1937), Cosas que fueron (1937) y Apostillas históricas (1945). 
Tiene especial interés que don Manuel haya fijado su atención en las virreinas, aspecto poco o nada considerado antes de él y del cual dice don Luis González Obregón en el prólogo a los "bocetos": “. . . asistimos a las reuniones en Palacio; las acompañamos en los paseos campestres; vamos a orar con ellas a los templos; les damos el pésame en sus pesares, y somos testigos aun de ciertas cosas intimas." Tal es, en efecto, el poder evocador de don Manuel, quien dedicó otro grupo de estudios a "procesiones y paseos", en los que nos lleva al Santuario de Guadalupe, a presenciar la imposición de borlas doctorales en la Real y Pontificia Universidad, 'a los funerales del marqués de Casafuerte y a tantos otros eventos más. La última serie tiene por título "El gran mundo colonial" y, como dice don Luis: "qué mayor alegría me puede proporcionar el Señor Romero de Terreros... edificándome con la piedad de los virreyes... presentándome al Excelentísimo Señor Don Fernando de Valenzuela, el llamado Duende... contándome al ó́do el enredo matrimonial con la famosa 'china'... poniéndome en relación con los Borda y otros potentados señorones... llevándome a los besamanos y saraos... y a la toma de hábito y cruzamiento de un Caballero de la Orden de Santiago... y al fin rematando con la deliciosa presentación de cuatro damas hermosisimas, 'Venus' y las 'Tres Gracias', o sean la famosa 'güera' Rodriguez y sus tres hijas, y refiriéndome después los detalles picarescos y las murmuraciones embozadas a que dieron margen ella y ellas por sus hechos y dichos". También trató don Manuel tradiciones y leyendas; entre las primeras "Los nacimientos" y "Cuadros de Navidad", y entre las segundas, "Relojero y asesino" y "La madre Mariana."

Todo lo anterior constituye algo así como la que llaman los franceses la petite histoire, mas no por eso, antes al contrario, deja de integrar la historia de la Nueva España.

Vengamos ahora a considerar brevemente, porque el asunto requiere estudio especial, uno de los aspectos más importantes de la obra de don Manuel, nos referimos al arte colonial, o sea el de la Nueva España.

Fue don Manuel uno de los primeros, estudiosos mexicanos que se interesaron en nuestro arte colonial; cuando apenas si se iniciaba su revalorización, él contribuyó a ella oportunamente, desde la segunda década del siglo, con sus trabajos históricos y críticos, guiado por un sentido estético que hemos tratado de caracterizar en, otro sitio, en El retablo de los reyes, 1959. Deciamos alli que el fondo de su gusto era clasicista, pero que el crítico fue subyugado, auténticamente por el licencioso arte barroco y el churriguera mexicano y, como por paradoja, si bien supo 
estimar algunas obras neoclásicas, el estilo, en general, le pareció que adolecía de cierta frialdad e insipidez. Esta posición que dijéramos ecléctica, mucho le honra, ya que pudo abrir su comprensión a diversas posibilidades; por otra parte, insistió en que el churriguera mexicano es distinto del español.

En 1916 publicó en forma de libro sus primeros "apuntes", como les llamó, sobre Arte colonial; dos años después apareció un segundo volumen y otro, tercero y último, en 1921. Reunió en esos pequeños volúmenes diversos estudios, algunos publicados antes como artículos, práctica que continuó siempre entre unos libros y otros. En 1922 vio la luz su Historia sintética del arte colonial, en la cual organizó anteriores y nuevos estudios, de manera que pudiera seguirse el asunto cronológicamente; pero, a la vez, dividido según las varias artes: Arquitectura, Escultura, Pintura y Grabado; añadió un capítulo totalmente novedoso, las Artes Industriales, que lo habian atraído desde un principio. Al siguiente año publicó un volumen especial dedicado al tema: Las artes industriales en la Nueva España (1923). Este libro hasta la fecha no tiene paralelo, pues nadie se ha ocupado después de él en estos aspectos. que tanto enriquecen la visión del arte colonial. En 1951 apareció $E l$ arte en México durante el virreinato, que, según don Manuel mismo dijo en la Advertencia, "es una nueva versión de nuestra Historia sintética del arte colonial", si bien ampliada y puede considerarse como el resumen de sus conocimientos. Mas, aparte de esas obras, quedan numerosos artículos sobre variados temas no recogidos en volumen. Las intenciones de don Manuel quedaron explícitas en la Introducción de la Historia sintética, pues escribió: “....admirador, como el que más, de las bellezas plásticas que nos legaron nuestros antepasados, he deseado coadyuvar a su estudio, con este epítome", y con su acostumbrada modestia agregó: "Ojalá que, a pesar de sus errores y omisiones, sirva de estímulo para estudiar y amar el arte colonial..."

En lo que se refiere a la Arquitectura de la Nueva España, don Manuel se interesó más por la civil y la campestre que por la religiosa, y también lo hizo por las obras de ingenieria hidráulica, como los acueductos. Parece natural que habiéndose ocupado en la vida social, lo hiciera asimismo en la arquitectura en que aquélla se desarrolló. Como ejemplo de sus estudios sobre residencias coloniales cabe considerar su trabajo sobre Una casa del siglo XVIII en México, la del conde de San Bartolomé de Xala (1957), modelo de monografia que incluye los inventarios de cuanto hubo en ella. Conexo al tema de las residencias está 
el de Los jardines de la Nueva España (1945), y las Fuentes virreinales (1967), que fue uno de sus últimos trabajos. Publić, además, un volumen sobre las Antiguas haciendas de México (1956), en el que considera algunos cascos del mayor interés; el tema, como otros que trató, era una positiva novedad. Sus varios articulos sobre los acueductos quedaron recogidos y aumentados en el volumen: Los acueductos en la historia y el arte (1949), un caso más de la originalidad del historiador y de su sentido estético. Por supuesto que escribió buen número de estudios sobre arquitectura religiosa, de aquellas obras vetustas que su amor lo llevaba a visitar: Acolman, Tepotzotlán, Tepeyanco, Atlatlauhcan, Ozumba, Huexotla, Ayotzingo, Acatlán, y tantos otros monasterios e iglesias de que supo hablar con buen sentido crítico y erudición. Para el IV Centenario de la Universidad de México, escribió una monografía sobre La iglesia y convento de San Agustin (1951), ahora Biblioteca Nacional. De Francisco Eduardo Tresguerras escribió una breve biografía, la primera que existe del ilustre arquitecto neoclásico.

No menos de veinticinco trabajos consagró don Manuel a la pintura colonial, de la que fue experto conocedor y excelente crítico; su acierto mayor en este campo fue haber identificado una serie de obras importantes como de El pintor Alonso López de Herrera (1984), entre ellas la espléndida tabla con La Asunción de la Virgen. En su estudio sobre la pintura anónima de La Plaza Mayor de México en el siglo XVIII (1946), cuadro de grandes dimensiones que perteneció a la Colección Alcázar y que ahora se encuentra en el Museo de Historia en Chapultepec, vertio no pocos conocimientos; y fue don Manuel quien hablo primero que otros sobre el gran cuadro de La Plaza Mayor de México en el siglo XVII, de Cristóbal de Villalpando, que se conserva en Inglaterra. Su último trabajo, publicado apenas antes de morir, fue sobre una pintura de la Misión de San Sabds en el provincia de Texas (1967).

Varios trabajos dedicó don Manuel a la Escultura que resumió en unos Breves apuntes sobre escultura colonial de los siglos XVII y XVIII (1980), que más tarde publicó en inglés la Gazette de Beaux-Arts. En cuanto al arte del Grabado, su investigación más importante está contenida en el volumen: Grabados y grabadores en la Nueva España (1948), pero descubrió algunas obras aisladas de gran interés artístico e histórico. El Grabado en hueco no podía menos que interesarle, ya que la numismática le habia atraido; asi, también publicó algunos estudios sobre medallas coloniales $y$ uno acerca del gran medallista 
neoclásico Jenónimo Antonio Gil, a quien puede considerarse fundador de nuestra Academia de San Carlos.

Lamento tener que abusar un poco más de vuestra atención, y pido mil perdones, pero no puedo dejar de mencionar siquiera los trabajos de don Manuel sobre nuestro siglo xix. Como en el caso de la Nueva España, del México Independiente se ocupó en la Historia politica y social. Veinte trabajos escribió sobre Agustin de Iturbide, su corte, su familia, su coronación, la Orden de Guadalupe, el destierro; en conjunto forman una interesante visión del Primer Imperio. También escribió sobre las veleidades de Santa Anna, Maximiliano y su corte, y los funerales de Juárez. Prologó la traducción de La vida en México, de Mme. Calderón, por Enrique Martínez Sobral (1920) y el mismo prólogo antecede la edición inglesa de Everyman's Library (1954). Fue el único historiador que se ocupó en el famoso Jockey Club de México, que estuvo en la Casa de los Azulejos.

Don Manuel supo gustar y estimar con mirada crítica el arte y en especial la pintura de nuestro siglo xux; a José María Velasco lo consideraba un gran paisajista, como lo es, y escribió un extenso trabajo sobre Los paisajistas mexicanos del siglo XIX (1943). También se ocupó en la obra del barón Gros, hijo del gran artista francés, quien estuvo en México, y de Daniel Thomas Egerton quien de sus dos largas visitas a nuestro pais, en el cual perdió la vida, dejó una copiosa obra, en su mayor parte poco conocida, y todavía publicó un artículo sobre Mateo Saldaña, pintor del siglo $\mathbf{x x}$.

No obstante esta especie de sucinto inventario que hemos hecho de la obra de don Manuel Romero de Terreros, con objeto de poner de relieve sus méritos, por demás indudables, apenas si hemos logrado sugerir una evocación y recordatorio de algunos de ellos; quedan pendientes los estudios que deben hacerse sobre tan multifacético e importante historiador y escritor que ganó con su pluma, como los buenos, la fama de hombre culto y erudito y el respeto y la admiración de sus lectores, como también el afecto profundo de cuantos nos honramos con su amistad.

Su muerte, acaecida el 18 de abril de 1968, marca la desaparición de uno de los últimos mexicanos representativos de ciertas tradiciones $y$ de toda una época.

La Academia Mexicana, Correspondiente de la Española, rinde homenaje en esta solemne ocasión a la memoria de don Manuel Romero de Terreros y Vinent, quien dio notable lustre a la cultura y a las letras de nuestro pais. 